\section{6世纪第一次中西交流中 的口译员形象}

\section{The Image of the Interpreter in the First Sino-Spanish Contacts (16th Century)}

victoria.beguelin-argimon@unil.ch

\author{
Victoria Béguelin-Argimón* \\ University of Lausanne \\ Faculty of Art \\ Lausanne, Switzerland 1015
}

在16世纪时期, 最早一批从菲律宾旅行至 中国的西班牙旅人因无法与中国人交流, 必 须仰赖口译员翻译, 但往往出于各种原因, 这些口译员并不常能以预期的忠诚态度来执 行他们的工作。这些口译除了身为翻译者, 也身兼向导、当地信息的提供者、最重要的 是也同时身为双方文化调解者。在第一批关 于中国与西班牙接触的文件中, 尤其是拉 达、罗阿尔卡、多尔德西雅思和桑切丝写于 1575 年至 1583 年之间的游记，让人们可以一 瞥口译员的身份、社会和地理来源、语言和 文化技能, 以及他们在调解各种任务状况中 所遇到的困难。也因此, 这些文件让第一批 传教士意识到需要学习中文的必要性, 而他 们也成为最早系统学习中文的西班牙人。
The earliest Spanish travelers in China coming from the Philippines (16th century), not being able to communicate in Chinese, have to trust interpreters who, very often and for the most diverse reasons, do not always carry out their work with the expected fidelity. These interpreters, beyond being mere translators, also function as guides, as informants about the territory and, above all, as cultural mediators. The first documents on Sino-Spanish contacts, especially Rada's, Loarca's, Tordesillas', and Sánchez' travel accounts, written between 1575 and 1583, allow to catch a glimpse of the interpreters' identity, their social and geographical origin, their linguistic and cultural skills, their various

* Dr. Victoria Béguelin-Argimón is senior lecturer at University of Lausanne (Switzerland) in Spanish language and linguistics. Her main research fields are Spanish as a Foreign Language and Spanish Medieval and Renaissance travel accounts to the East that she analyses mainly from a linguistic perspective. 
16世纪第一次中西交流中的口译员形象

22

[关键词] 翻译历史; 口译历史; 语言接 触; 传教士语言学; 文化研究; 明朝; 在中 国的西班牙旅人
The Image of the Interpreter in the First SinoSpanish Contacts (16th Century)

tasks in mediation as well as the difficulties they have to deal with in their work. The documents also allow to perceive the need for the first missionaries to learn Chinese and their very first attempts to do so.

Key words: translation history; interpretation history; language contact; missionary linguistics; culture studies; Ming Dynasty; Spanish in China.

\section{Introducción}

Del vivo interés que suscitan en la Corona las lenguas de las tierras nuevamente colonizadas en Indias y, en especial, la comunicación con los habitantes de estas, son botones de muestra tanto las ordenanzas, cédulas reales e instrucciones sobre los intérpretes emitidas desde el año $1526^{1}$, como los cuestionarios elaborados desde mediados del siglo XVI por el cronista y cosmógrafo oficial de las Indias, López de Velasco, en los que se busca recabar información acerca de la situación lingüística y la presencia de intérpretes, indispensables para la mediación entre naturales y castellanos ${ }^{2}$. Mientras que ya son abundantes los estudios realizados sobre los intérpretes y su labor en las Indias Occidentales ${ }^{3}$, hay que señalar que es menor la atención que ha suscitado esta figura en las llamadas Indias Orientales, sobre todo por lo que se refiere a uno de los episodios de contacto lingüístico de los que fue escenario esta región, el de las relaciones entre la

\footnotetext{
${ }^{1}$ A modo de ejemplo, recordemos algunos de estos textos jurídicos reunidos por de Solano (1991) sobre los intérpretes: "Ordenanzas reglamentando que en cada expedición de descubrimiento y conquista se lleven intérpretes que puedan explicar a los indios la calidad política y religiosa de la empresa española" (1926); "Real cédula castigando con penas de destierro y pérdida de bienes a los intérpretes indios de las audiencias que acepten regalos y presentes de los otros indios" (1529); "Real cédula a la segunda Audiencia de Nueva España apuntando que las declaraciones de los indios sean traducidas por dos intérpretes, para evitar fraudes e irregularidades en la interpretación de las lenguas"; "Ordenanzas para los intérpretes de las Audiencias de Indias" (1563); "Instrucciones sobre los nuevos descubrimientos por mar: Ordenando que en las expediciones lleven intérpretes que faciliten los primeros encuentros y para que informen sobre las características políticas y calidades económicas de la tierra".

2 Para estos cuestionarios ver de Solano (1988).

${ }^{3}$ Ver, por ejemplo, de Solano (1975) y (1991: XXXV-XLII); Martinell Gifré (1988: 59-99) y, especialmente, Alonso Araguás (2005).
} 
comunidad hispana y la china. Este encuentro entre culturas y lenguas tan distintas merece más atención de la que ha recibido hasta la fecha ${ }^{4}$.

Es bien sabido que, a lo largo de la historia y pese a su importantísima labor, los intérpretes han sido a menudo personajes anónimos cuyas huellas hay que rastrear en documentos de todo tipo para conseguir dotarlos de identidad. Saber quiénes fueron, qué edad tenían cuando desempeñaron su cargo, de qué medio social procedían, cómo aprendieron la lengua, en qué momentos se recurría a ellos, cómo se les consideraba, qué nivel de conocimiento lingüístico tenían, qué tareas realizaban o hasta qué punto daban prueba de fidelidad en su trabajo son algunas de las cuestiones que el análisis de documentos del siglo XVI relativos a los primeros contactos sino-hispánicos permite vislumbrar. Efectivamente, los textos relativos a la expedición del agustino Martín de Rada $^{5}$ y del encomendero Miguel de Loarca a China en 1575, a la incursión en territorio imperial del franciscano Agustín de Tordesillas y el militar Francisco de Dueñas en 1579, y a los periplos del jesuita Alonso Sánchez en tierras del Imperio Celeste entre 1583 y 1585, plasman episodios de (des)encuentro entre españoles y chinos en los que se percibe cómo el intérprete desempeña, para bien o para mal, un papel capital. Estos textos-relaciones de viajes de los propios viajeros, e informes y epístolas de remitentes varios dan voz, además, a los que empiezan a reclamar la necesidad de aprender la lengua china para poder así prescindir de unos intermediarios no siempre apreciados ${ }^{6}$.

\section{Primeros contactos sino-hispánicos}

Poco tiempo después de su llegada al archipiélago filipino en 1565, los españoles se establecen en la isla de Luzón y en 1571 conquistan su núcleo de población más importante, la ciudad de Manila. Las costas del Imperio Celeste quedan a escasos días de navegación y, aunque los contactos entre chinos e isleños daten ya de antiguo ${ }^{7}$ y que existan "testimonios sobre la presencia de un comercio chino en la zona previo a la llegada de los

\footnotetext{
${ }^{4}$ Como sostiene Klöter (2011: 31), “[t]he Spanish-Chinese encounter in the Philippines contributed an important, albeit largely neglected chapter to the history of Chinese linguistics".

${ }^{5}$ Para una biografía de Martín de Rada ver Folch (2008).

${ }^{6}$ Los documentos empleados para el trabajo se encuentran detallados en la bibliografía y proceden de la página La China en España. Elaboración de un corpus digitalizado de documentos españoles sobre China de 1555 a 1900, disponible en https://www.upf.edu/asia/projectes/che/principal.htm.

${ }^{7}$ Klöter remite a Yang, que remonta los primeros contactos entre China y Filipinas al año 661 (Yang, 2007, citado por Klöter, 2011: 32).
} 
españoles" (Ollé, 2000: 37), el asentamiento de estos en Filipinas aumenta considerablemente la demanda de mercancías procedentes del Imperio. En 1567, las autoridades de este territorio emiten un decreto que legaliza el comercio de sus súbditos en tierras extranjeras (Ollé, 2000: 44) lo que incrementa el tráfico mercantil entre las costas chinas y Manila, al tiempo que crece el número de comerciantes que se afincan de forma más o menos permanente en el barrio chino de la capital, el Parián, estrechando lazos con los españoles ${ }^{8}$. A estos comerciantes, procedentes en su mayoría de la región del Fujián, se les conocerá con el nombre de sangleyes. Con ellos llegan también al Parián, chinos que trabajan como artesanos, agricultores, pescadores, mano de obra no especializada y sirvientes ${ }^{9}$, prestando así un necesario servicio a los colonos. La que en 1570 es todavía una pequeña colonia de chinos alcanzará treinta años después la cifra de 20.000 habitantes ${ }^{10}$.

No obstante, objetivos muchísimo más ambiciosos respecto a China que los puramente comerciales son los que albergan los españoles quienes, esperando continuar su expansión territorial y misional, evalúan seriamente las posibilidades de conquista del Imperio Celeste; es por ello fundamental informarse acerca de esta tierra. Los españoles recaban datos no solo a través de los portugueses y de los naturales de Filipinas sino, sobre todo, gracias a las relaciones directas con los propios chinos en el Parián manilense, donde las autoridades políticas y religiosas españolas intentan tender puentes con unos vecinos que mantienen sus fronteras cerradas a cal y canto a cualquier extranjero. Una carta de Rada da fe de las vías por las que llega el conocimiento sobre China: "avnque según me é ynformado, así de portugueses como de yndios, que tratan con ellos, como de vn chino que tomaron los días pasados en vn junco, la gente de china no es nada belicosa" (Rada, 1569). Si bien la información se consigue a menudo a través de chinos instalados en Manila - "[t]ienen las casas de cal y canto y de ladrillo, las ciudades muradas y de silleria y segun la relacion de un chino principal, llamado Canco, que tuve yo en nuestra casa de çubú casi medio año" (Rada, 1572)-, es solo la experiencia directa y vivida la que se considera realmente fiable: "[e]sto y otras cosillas se

${ }^{8}$ Ollé (2000: 39) menciona una relación de mayo de 1570 con las primeras referencias a la presencia de una colonia de 40 chinos casados y 20 japoneses.

${ }^{9}$ Chia (2006: 515), citado por Klöter (2011: 160).

${ }^{10}$ Wickberg (1965: 4-6), citado por Klöter (2011: 32). Para un estudio sobre las relaciones entre los españoles establecidos en Filipinas y los chinos, ver Jacquelard (2015: 333-379). 
supieron por la relacion de aquel chino que hasta que se vean no se pueden tener por ciertas" (Rada, 1572). Otros documentos dan fe igualmente de estos tempranos contactos entre chinos y españoles (Ollé, 2000: 39-46) que permiten a estos últimos adquirir unos conocimientos básicos sobre el codiciado territorio.

Sin embargo, el vaivén entre las Filipinas y las costas del Fujián, además de ser un movimiento comercial, es también un movimiento lingüístico y de esta navegación entre lenguas, fundamental para el buen entendimiento de las dos comunidades, es protagonista privilegiado el intérprete.

\section{Cómo se denomina a los intérpretes y quiénes son}

Veamos, en primer lugar, cómo se nombra a esta figura en los textos estudiados. Los términos que aparecen en los documentos americanos de los siglos XVI y XVII para designar al que realiza el papel de mediador lingüístico y cultural son bozal, chasque, faraute, intérprete, lengua, indio lengua, lenguaraz, ladino, indio ladino, nahuatlato (y su variante naguatlato), trujamán y trujimán ${ }^{11}$. En la documentación manejada sobre los contactos sino-hispánicos, se encuentra intérprete (el término más frecuente), lengua y ladino, mientras que la voz nahuatlato solo aparece con las variantes navatato (Rada), naglatlate (Loarca) y naguatato (Loarca, Alfaro, Salazar, Sande). Cabe señalar que este último término, neologismo americano, salta de las Indias a las Filipinas para designar la misma realidad.

Los intérpretes son, en su mayoría, sangleyes y ya se ha visto que Martín de Rada individualiza, dándole nombre, a alguno de ellos como a aquel "chino principal, llamado Canco, que tuve yo en nuestra casa de çubú casi medio año" (Rada, 1572). Sinzai, un mercader del que Loarca dice "que trata aquí en Luçon" (Loarca, 1575: 118) funcionará en 1575 como mediador en las negociaciones previas al viaje de Rada y Loarca a China entre los españoles y el pirata Lin Feng llamado Limahon en las fuentes hispánicas, así como de intermediario lingüístico y cultural durante el propio viaje.

En los diversos textos que informan sobre esta primera expedición de españoles a China, aparecen otros datos que permiten ir perfilando la figura

11 Ver Martinell (1988: 61); de Solano (1991: XXXVII) y Alonso Araguás (2005: 32-39). Para las voces utilizadas en la Edad Media para designar a los traductores e intérpretes, ver Alvar (2010) y, especialmente, Rubio Tovar (2011). 
del intérprete. Amén de la ayuda del comerciante Sinzai, Rada y Loarca contarán durante el periplo con un intérprete oficial, "un chino llamado hernando detang'" que, en palabras del propio Rada (1575: 17), funciona como intérprete o lengua. En un informe sobre la expedición, el gobernador Francisco de Sande especifica que el agustino y el encomendero "llevaron vn chino, que se llama hernando, por naguatato, que sabe el español" (Sande, 1576). Probablemente se tratara de un chino esclavo, convertido al cristianismo, como se deduce de los detalles suministrados por Loarca quien nos dice de Hernando que era "indio esclavo christiano, y lengua" (Loarca, 1575: 119). La precisión de Loarca permite poner de relieve dos características frecuentes de los que funcionan como intérpretes en las relaciones sino-hispanas: por un lado, su posible condición de esclavos y, por otro, su condición de cristianos conversos.

En una carta de 1582, el agustino Francisco de Ortega ofrece información complementaria sobre el perfil de los intérpretes, adscribiéndolos a la comunidad manilense de chinos convertidos. Después de referirse a "Hernando de San Agustín", el intérprete de Rada y Loarca, Ortega nombra a otros dos "que se llaman miguel de Sant Nicholás y francisco de San Pablo, que todos estos saben nuestra lengua y la suya de china" (Ortega, 1582).

Durante la segunda expedición desde las Filipinas a China, la comitiva del franciscano Tordesillas cuenta con un intérprete del que González de Mendoza dice que era "un muchacho chino que sabía la lengua española y le habían tomado en la guerra del corsario Lymahon" (González de Mendoza, 2008: 255), es decir que lo habían apresado unos años antes durante el episodio que enfrentó a los españoles con el pirata chino Lin Feng y que había sido reducido a la condición de esclavo. González de Mendoza precisa que el intérprete es un "muchacho" lo que permite perfilar otro rasgo del intérprete, en este caso sobre su edad, pues, efectivamente, era frecuente emplear a jóvenes para estos menesteres. Quizás el mismo intérprete al que se refiere González de Mendoza sea el chino "que se hauia hecho cristiano" mencionado por Tordesillas (1578) y que les acompaña en su viaje, probablemente con el objetivo de mediar lingüística y culturalmente. Otro miembro de la expedición, Pedro de Alfaro, identifica a este intérprete mediante un nombre propio como "Juanico el sangley que traiamos por interprete" (Alfaro, 1579). Se trata, probablemente, como se deduce de su nombre, de un chino convertido al cristianismo y joven como deja imaginar el diminutivo aplicado a su nombre.

A uno de estos intérpretes chinos convertidos pensaban haber encontrado los franciscanos Tordesillas y Alfaro cuando conocieron a un tal 
Simón en China, aunque muy pronto se percataron de que se trataba de un perjuro: “Después toponos Dios con otro apostata y renegado que quiso y se offreçio a hazer nuestros negoçios vendiendosenos por christiano llamado Simon" (Alfaro, 1579). Este intérprete causará importantes problemas a la expedición.

\section{Qué lenguas conocen y qué competencia tienen en ella}

La documentación estudiada esconde cómo aprendieron el español los intérpretes chinos y si hubo un proceso de aprendizaje definido. Según Borao,

[a]l ser los chinos quienes iban a Manila, a ellos era a quienes correspondía el mayor esfuerzo, habiendo de aprender el castellano; y ciertamente lo lograban. No sabemos cómo lo hacían, pero sin duda ensayarían desde muy pronto métodos más allá de la pura inmersión, por utilizar el término que actualmente se usa. (Borao, 2012: 26).

Sin embargo, los textos sí dan precisiones sobre el muy variable nivel de competencia de los que funcionan como intérpretes. Francisco de Sande explica en una carta que Tordesillas llevaba en su expedición a un "naguatato [...] de aquí [que] no sabía bien la lengua" (Sande, 1580), refiriéndose, probablemente, al ya mencionado Juanico del que habla Pedro de Alfaro en otra misiva.

Una anécdota permite vislumbrar otro caso de conocimiento lingüístico deficiente. Durante el viaje de Rada y Loarca, las autoridades chinas desean entrevistarse con el encomendero Loarca y le piden que les visite, precisándole que no es menester que le acompañe el intérprete oficial de la comitiva española pues las propias autoridades aseguran disponer de intérpretes para realizar la mediación. Sin embargo, cuando Loarca llega a la cita se encuentra con

un chino que sabia un poco la lengua de los Indios de las Islas, pero era tan poco que negocio de importancia no se podia tratar con el, i mas aviendo de hablar por otro naguatato, porque no toda la gente sabe la lengua cortesana ques la que habla la gente principal. (Loarca, 1575:127-128).

Las palabras de Loarca dejan pensar que el intérprete al servicio de las autoridades chinas debía de desconocer el español pues el encomendero solamente se refiere a las limitadas competencias de este en la lengua de 
"los Indios de las Islas", lengua en la supuestamente hubiera tenido que comunicar Loarca con el intérprete chino. Pero además, las palabras de Loarca permiten entrever una característica fundamental del entramado lingüístico del sureste asiático donde las lenguas locales conviven con el mandarín, la lengua de la élite letrada. Loarca precisa que el intérprete que trabaja para las autoridades chinas necesita de otro intérprete pues el primero desconoce la lengua cortesana, el mandarín. Efectivamente, la lengua hablada por los que solían mediar entre españoles y chinos no acostumbraba a ser el mandarín sino la lengua de la región del Fujian, el minnanhua o fujianés, por lo que la comunicación con las autoridades chinas, hablantes de mandarín, podía verse gravemente perturbada por el desconocimiento de esta lengua -o un conocimiento deficiente-por parte de algunos intérpretes.

En la carta de 1582 ya mencionada, el agustino Francisco de Ortega observa el adecuado nivel de competencia en español de los chinos cristianizados Hernando de San Agustín, Miguel de Sant Nicholás y Francisco de San Pablo, y añade que hay otros chinos cristianos "que saben la lengua de las yslas y la de china y mucha parte de la nuestra" (Ortega, 1582) aunque precisa que el nivel de competencia de estos últimos es menor que la de los tres primeros, individualizados por sus nombres. Los documentos arrojan luz así sobre la presencia en Manila de chinos que, aun con competencias medianas en español, podrían funcionar como mediadores, llegado el caso.

Otra lengua vehicular para la comunicación entre españoles y chinos va a ser el portugués. Efectivamente, a veces la mediación lingüística entre miembros de estas dos comunidades lingüísticas no se realiza a través de un chino que habla español sino a través de alguno que sabe portugués. Sánchez menciona que, en una ocasión, los chinos recurrieron a "una lengua que sabía un poco de portugués y entendía casi nada de castellano" (Sánchez, 1583). Sería interesante saber en qué medida los chinos que funcionaron como intérpretes para los españoles tenían ya conocimientos previos, aunque solo fueran superficiales, del portugués pues tal conocimiento, obviamente, les tenía que facilitar el aprendizaje del español.

\section{Leer y escribir a través del intérprete}

En las relaciones de viajes, se plasman a menudo los intercambios orales entre españoles y chinos que parecen fluir de modo directo entre los interlocutores pues, aunque el mediador está necesariamente presente, solo se le suele mencionar cuando surgen problemas en la comunicación. Pero, además de esta mediación lingüística oral, la más frecuente, los intérpretes funcionan también como traductores y glosadores de libros en 
lengua china. Durante el primer viaje de los españoles al Imperio, sabemos que Rada adquiere una serie de libros sobre los más variados temas que le servirán para recabar información acerca del territorio y sus habitantes (Folch, 2018). Hay que imaginar que la colaboración de los intérpretestraductores fue indispensable para leer las obras compradas pese a que Rada no precise nada al respecto. Sí lo hace, en cambio, González de Mendoza en su Historia del Gran Reino de la China cuando alude a los intérpretes que tienen como misión traducir libros para ponerlos al alcance de los castellanos:

Estos y muchos trajeron los dichos Padres, de donde, como he dicho, se han sacado las cosas que se han dicho y dirán en este libro de historia, interpretadas por personas nacidas en la China y criadas en las Islas Filipinas en compañía de los españoles que en ellas residen. (González de Mendoza, 2008: 130).

Otra de las numerosas tareas del intérprete es la de traducir cartas. La relación de Loarca - no así la de Rada- recoge los textos íntegros en castellano de las cartas que acompañaron a los castellanos destinadas a las autoridades chinas y la traducción al castellano de las respuestas a estas. La traducción de estas misivas del castellano al chino y viceversa la lleva a cabo principalmente Sinsay, el sangley que media en el viaje, pero también otro personaje, Oumoncon, el capitán del barco que trasladará a los españoles hasta China. Del primero se precisa que también tradujo la carta que escribió el Maese de Campo a Lin Feng durante las negociaciones previas a la captura del pirata por parte de los españoles: "escrivio el Maese de Campo por lengua de Sinzai, nuestro chino, la carta siguiente a Limahon" (Loarca, 1575: 116).

Francisco de Sande alude a las cartas traducidas, "que vinieron de china originales, trasuntadas en español" (Sande, 1576), es decir que se podían leer tanto en chino como en español y para cuya traducción los intérpretes habían sido eslabones imprescindibles. Alonso Sánchez se refiere igualmente a cartas escritas por españoles y precisa que fueron traducidas al chino "por medio de uno de los capitanes que de la ciudad de Chincheo bienen a contratar a la de Manila" (Sánchez, 1583).

En los textos, observamos además que, a veces, los españoles prefieren comunicar por escrito en vez de oralmente con los chinos, como revelan las siguientes palabras de Loarca:

$Y$ viendo que no se negociava nada con el yendo les a hablar porque luego nos despedian, determinó el padre fray Martin de Rada 
que se le escriviese una carta dandole quenta de como la causa principal de nuestra venida era para tratar y asentar paz y amistad con ellos y para quedarçe alla los padres. (Loarca, 1575: 131).

El viajero precisa, sin embargo, que "[n]o avia quien nos quisiese escribir la carta" y que, al fin, "el capitan Oumoncon la escrivio aunque con themor" (Loarca, 1575: 131), lo que evoca los importantes peligros que suponía para un chino encontrarse en ciertas tareas de mediación, como veremos más adelante.

Además de la traducción de cartas, los textos documentan también la traducción de libros. González de Mendoza se refiere a un

libro propio que los Chinos tienen, donde ponen por extenso, la grandeza del Reyno y de las quinze Provincias que tiene en si. Este libro se traxo a la ciudad de Manila, estampado en la mesma China, y se traduxo a nuestra lengua por interpretes que son Chinos de nacion; y por ser Christianos baptisados, se han quedado, en las dichas islas por moradores, (González de Mendoza, 1585: 42).

Y Loarca se refiere a lo que podrían ser las más tempranas traducciones de oraciones del español a la lengua china pues cuenta que, en una ocasión, la autoridad de la ciudad donde se encuentran

pidio le embiasemos alguna cosa escrita de nuestra mano. Embiole el padre frai Martin las oraciones del pater noster y ave maria y los mandamientos de la ley de Dios y una oracion declarada en su lengua. Respondio que todo aquello era muy bueno y a el le parecia muy bien. (Loarca, 1575: 131).

\section{Mediar entre culturas}

Los intérpretes no aseguran solamente un puente lingüístico sino también cultural. Conocen el territorio, el funcionamiento de las instituciones, las jerarquías administrativas $y$, sobre todo, una serie de códigos que pueden producir choques culturales y traducirse en conflicto entre los naturales y los visitantes, produciendo sentimientos de inseguridad, desconcierto o agravio en cada una de las partes. El lenguaje corporal o la función de los obsequios, por ejemplo, forman parte de la cultura de los intérpretes y, frente a la dificultad de los españoles para comprender que se trata de códigos culturales muy a menudo de carácter ritual, orientan a los extranjeros y les enseñan cómo comportarse. Si son muchas las costumbres chinas que sorprenden a los viajeros, las que más 
les afectan son las que les obligan a un cambio de comportamiento y estas son objeto de duras negociaciones con las autoridades imperiales a través de los intérpretes. Detengámonos en dos ejemplos paradigmáticos: el modo de transporte propuesto por las autoridades chinas a los viajeros de la primera expedición - tienen que desplazarse en sillas portadas en andas- y la obligación de prosternase al hablar con las autoridades imperiales. Los religiosos rechazan ir

en hombros de hombres, pero los capitanes que yvan co nosotros dixeron que se enogaria el inçuanto con ellos sino cumplian su mandamiento y tambien porque nos tenian por gente baxa sino nos llevavan de aquella manera porque alla la gente honrrada toda anda en sillas aunque sea por la çiudad (Rada, 1575: 17) ${ }^{12}$.

Son los capitanes, a través de los intérpretes, los que explican a los españoles las razones de esta manera de desplazarse.

Rada y Loarca se revelan también contra otra práctica, la de tener que hablar de rodillas a los gobernantes chinos, gesto ritual que ya había disgustado a otros viajeros ilustres del medioevo como el franciscano Guillermo de Rubrouck cuando llegó a la corte del Gran Khan en $1254^{13}$. El relato de Rada deja ver cómo el intérprete les transmite la inflexibilidad de las autoridades chinas:

el [gobernador] embio primero por nuestro interprete y nos embio a dezir por el que aviamos venido hasta alli por su mandato y que si queriamos verle aviamos de hazerle la mesma cortesia que sus capitanes le hazian que era hincarnos de rrodillas a la salutaçion y que sino lo queriamos hazer que nos podiamos bolver desde alli al puerto, (Rada, 1575: 18).

Pese a los argumentos de los viajeros castellanos, las negociaciones son en vano y el intérprete es tajante en cuanto al comportamiento que es necesario adoptar:

Respondionos que bien deziamos, que a el que le hablasemos como se acostumbrava en Castilla, pero que al virrey forçoso se le avia de hablar de rodillas. (Loarca, 1575: 128).

\footnotetext{
${ }^{12}$ Se transcriben las citas de la relación de Rada separando las palabras para facilitar su lectura.

${ }^{13}$ Para este tema, ver el estudio de Guéret-Laferté (1998).
} 


\section{Intérpretes traidores}

La labor de los intérpretes en China es delicada pues muy a menudo tienen que transmitir mensajes que desagradarán a las autoridades lo que puede acarrearles gravísimos problemas. Así se explican, en gran medida, las infidelidades en las que incurren una y otra vez estos mediadores. Refiriéndose a la expedición de Tordesillas, Francisco de Sande lamenta que los viajeros no contaran con un "naguatato fiel" y el propio cabeza de la expedición, Pedro de Alfaro, se expresa en duros términos sobre uno de los intérpretes, el chino convertido al cristianismo llamado Simón, del que descubren que es "apóstata y renegado" y al que Pedro de Alfaro no se contenta con tildar de "traidor" sino que incluso califica de "hijo de satanás": "[e]l hijo de Satanas de tal manera nos engañava y falseava y dava alla sus preguntas y respuestas que diziendo nosotros uno el dezia otro".

El jesuita Sánchez, por su parte, rechaza de plano el empleo de intérpretes que "no usan decir la verdad antes se precian de mentir todos y saber jurar y burlar armar enbustes". Engaño, falsedad, cambio de propósitos, traición, engañar, falsear, fingir, trastocar las palabras, mentir, jurar, burlar, mudar, decir al revés, armar embustes, decir nosotros uno el decir otro, no usar decir la verdad, decir muy diferentemente: todas estas voces y sintagmas dan fe de las quejas continuas por parte de los viajerossobre la falta de veracidad de los intérpretes en el desempeño de su labor.

Los intérpretes chinos tienen, no obstante, razones más que fundadas para falsear las traducciones y una cita, entre otras muchas, ilustra el miedo que sienten de traducir lo que se les pide:

un chino ladino que allá estava supo que el yntérprete no dezía cosa alguna de lo que los padres les dezían [...] preguntándole este testigo y los dichos padres al dicho yntérprete que porque no avía dicho la verdad, respondió que no la avía osado dezir porque si la dixera a él y a ellos los matarían a açotes. (Salazar, 1583).

De su viaje, Pedro de Alfaro explica que el intérprete que llevaban: "fingio el lo que quiso porque le paresçio que si dezia lo que yo que le cortarian la cabeça como el despues nos lo disco". Y Sánchez ratifica la dureza de los castigos impuestos a los intérpretes:

en diciendo las lenguas algo que derogue en algo a la autoridad y reberencia de ellos [de los mandarines], luego le azotan cruelmente, y 
todas las faltas que face el estranjero con sus crianzas y cerimonias las paga la lengua. (Sánchez, 1583).

Sánchez precisa que "[n]inguna cosa les costará a ellos más cara que decir a los manderines que les queremos enseñar nueva ley y costumbres" (Sánchez, 1583). Vemos, pues, que los castigos por transmitir palabras o peticiones desagradables a las autoridades pueden oscilar desde los azotes hasta la pena de muerte para los traductores e incluso para los viajeros. Por ello, los intérpretes se sirven de la astucia y son capaces de transformar las palabras de todos sus interlocutores sin que estos se percaten de nada.

Tales traiciones linguísticas no solo se producen en el ámbito oral sino también en el escrito. En una misiva de Francisco de Sande (1576) dirigida a Felipe II, el gobernador de Filipinas explica cómo se había falseado la traducción de las cartas escritas por su predecesr en el puesto, Guido de Lavazares, en las que este informaba a las autoridades chinas sobre la captura de Lin Feng por parte de los españoles. Las traducciones, realizadas por Omoncón y Sinsay, presentan al capitán Omoncón como principal adalid en la lucha contra el pirata con el objetivo de obtener honores y recompensas pecuniarias de los chinos, tal como efectivamente ocurrió pues ambos recibieron "dinero, demás de la capitanía, a cada quatroçientos taes de plata, que pesa cada tae doze reales de castilla" (Sande, 1576).

\section{A modo de conclusión: aprender la lengua para poder prescindir de los intérpretes}

La política lingüística española en América fomentó el aprendizaje de las lenguas de los naturales sobre todo con fines de predicación. En China, territorio no colonizado, se requería que los misioneros pudieran servir de puente entre las instancias políticas españolas y chinas, y comunicar de manera efectiva y directa con las autoridades para obtener permisos de entrada, estancia y asentamiento en el territorio: los intérpretes se habían mostrado una y otra vez totalmente ineficaces en este tipo de negociación y además, como comenta Sánchez, comunicarse a través de un intérprete resultaba tan extraño para los chinos que la propia situación les producía hilaridad: "hablar por intérprete parece más cosa de risa para ellos" (Sánchez, 1583).

Las fuentes documentales testimonian de la temprana voluntad de los misioneros de aprender la lengua. En una carta al Virrey de Nueva España, Rada argumenta la importancia de enviar a religiosos a China para que aprendan el idioma y expresa su interés personal en hacerlo: 
y aunque no fuese más de servir de lenguas y que se pudiese contratar con ellos, no sería poco importante su ida, y para ello, si a mí me lo mandasen, lo ternía por particular merced, y lo haría de muy buena voluntad (Rada, 1572).

Tordesillas menciona que algunos ya han empezado a aprender la lengua, como en el caso de Fray Esteban Ortiz "el qual se daua a deprender la lengua china con gran cuidado" (Tordesillas, 1578: 1) y que, según González de Mendoza, "la sabía ya razonablemente" (González de Mendoza, 1585: 251).

Pedro de Alfaro piensa que, a falta de intérpretes fieles, es necesario aprender la lengua antes de continuar las negociaciones con los chinos:

yo holgara si el señor fuera servido que alguno de nosotros supiera la lengua o tuvieramos persona fiel que sin miedo pudiera declarar el effecto de nuestra venida, mas no fue tal nuestra dicha, todavia por semejar y por mostrar las ymagines y libros y otros señales declaramos algo de nuestro intento mas no como era razon y yo quisiera, sera el señor servido que sabida la lengua y mejor dispuesto con su divina gracia se trate el negocio el año que viene (Alfaro, 1579).

De hecho, uno de los argumentos principales que los misioneros arguyen para justificar la urgencia de aprender chino es la necesidad de poder prescindir de unos intérpretes cuya labor se critica. El obispo Domingo de Salazar refiriéndose a los jesuitas explica que "los padres de la compañía, viendo el poco rremedio que por medio de los yntérpretes tienen para poder dezir alguna cosa, procuran de prender la lengua para poder hablar con ellos" (Salazar, 1583).

Sin embargo, son ni más ni menos que los propios intérpretes chinos los que van a encargarse de enseñar la lengua a los misioneros, como leemos en una carta en la que Santiago de Vera (1589), gobernador de las Filipinas, explica que dio "yntérpretes para que les enseñasen la lengua" a los misioneros. Así pues, con las actividades de enseñanza de la lengua, los intérpretes completan su importante labor como mediadores entre españoles y chinos en los intercambios orales, en la traducción de cartas y oraciones, en la glosa de libros y en las situaciones de conflicto cultural. 


\section{BIBLIOGRAFÍA}

Alfaro, P., 1579. La carta de Frai de Alfaro a Frai Juan de Ayoza Guardián de Nuestra Señora de los Ángeles y Comunes, en Manila su fecha en la ciudad y Río de Cantón a 13 de octubre 1579. https://www.upf.edu/ asia/projectes/che/s16/alfaro.htm.

Alonso Araguás, I., 2005. Intérpretes de Indias. La mediación lingüística y cultural en los viajes de exploración y conquista: Antillas, Caribe y Golfo de México (1492-1540). Tesis doctoral. Salamanca: Universidad de Salamanca, Facultad de traducción y documentación. http://hdl. handle.net/10366/116145.

Alvar, C., 2010. Traducciones y traductores. Materiales para una historia de la traducción en Castilla en la Edad Media. Alcalá de Henares: Centro de Estudios Cervantinos.

Borao, J. E., 2012. La "Escuela de traductores de Manila": Traductores y traducciones en la frontera cultural del Mar de China (Siglos XVI y XVII). In I. Donoso Jiménez (coord.), Historia cultural de la lengua española en Filipinas ayer y hoy. Madrid: Verbum: 23-52.

Folch, D., 2008. Biografía de Martín de Rada. Huarte de San Juan. Geografía e Historia, 15: 33-63.

--, 2018. Martín de Rada's Book Collection. Sinología Hispánica. China Studies Review, 6, 1: 1-26.

González de Mendoza, J., 1585. Historia de las cosas más notables, ritos y costumbres del Gran Reino de la China. (Roma edición). Madrid: Miraguano, 2008.

Guéret-Laferté, M., 1998. Les gestes de l'autre. In Le geste et les gestes au Moyen Âge. Aix-en-Provence: Presses universitaires de Provence. Disponible en: http://books.openedition.org/pup/3509.

Jacquelard, C., 2015. De Séville à Manille, les Espagnols en mer de Chine.1520-1610. Paris: Les Indes Savantes.

Klöter, H., 2011. The Language of the Sangleys: A Chinese vernacular in missionary sources of the seventeenth century. (Sinica Leidensia, 98.). Leiden \& Boston: Brill.

Martinell Gifré, E., 1988. Aspectos lingüísticos del descubrimiento y de la conquista. Madrid: Consejo Superior de Investigaciones Científicas (CSIC).

Loarca, M. de, 1575. Relacion del viaje que hezimos a la China desde la ciudad de Manila en las del poniente año de 1575 años, con mandado y acuerdo de Guido de Lavazaris governador i Capitan General que a la 
sazon era en las Islas Philipinas. https://www.upf.edu/asia/projectes/ che/s16/loarca.htm.

Ollé, M., 2000. La invención de China. Percepciones y estrategias filipinas respecto a China durante el siglo XVI. Wiesbaden: Harrassowitz Verlag.

Ortega, F. de, 1582. Respuesta que dio Fr. Francisco de Ortega, de la Orden de San Agustín a las objeciones que se le hacían para suspender la prosecución de lo del presente para el Rey de China. https://www.upf. edu/asia/projectes/che/s16/orte1582.htm.

Rada, M. de, 1569. Copia de carta del P. Martín de Rada al Virrey de México, dándole importantes noticias sobre Filipinas. Cebú, 8 de julio de 1569. http: / / www.upf.edu/asia/projectes/che/s16/rada1569.htm.

--, 1572. Copia de una carta quel Padre fray martin de rrada provincial de la orden de San Agustin que reside en la china escribe al virrey de la nueva spaña fecha en la ciudad de manilla a 10 de agosto de 1572. http://www.upf.edu/asia/projectes/che/s16/rada2.htm.

--, 1575. Relaçion Verdadera delas cosas del Reyno de Taibin por otro nombre china y del viaje que ael hizo el muy Reverendo padre fray martin de Rada provinçial que fue delaorden delglorioso Doctor dela yglesia San Agustin. quelo vio yanduvo en la provinçia de Hocquien año de 1575 hecha porelmesmo. https://www.upf.edu/asia/projectes/che/ s16/radapar.htm.

Rubio Tovar, J., 2011. El vocabulario de la traducción en la Edad Media. Alcalá de Henares: Universidad de Alcalá. Servicio de Publicaciones.

Salazar, D. de, 1583. Ynformacion sobre los impedimentos a la predicación en China realizado por el obispo Domingo de Salazar para el Papa Gregorio XIII y el rey Felipe II. Manila 19 de Abril de 1583. https: / /www.upf. edu/asia/projectes/che/s16/salazar2.htm.

Sánchez, A., 1583. Relación breve de la jornada quel P. Alonso Sánchez dela Compañía de Jesús hizo por horden y parezer del SR. D. Gonzalo Ronquillo de Peñalosa, governador de Philipinas, y del Sr. obispo y oficiales de S.M. desde la Isla de Luzón y ciudad de Manila a los Reynos de la China. Manila, abril-junio 1583. https://www.upf.edu/asia/projectes/che/s16/sanchez2.htm.

Sande, F. de, 1576. Carta a Felipe II del Gobernador de Filipinas, doctor Sande. Da cuenta de su llegada y accidentes de su viaje; de la falta que hay allí de todo, y habla de Religiosos, minas, de la China, Mindanao, Borneo, etc. https://www.upf.edu/asia/projectes/che/s16/sande1576. htm. 
--, 1580. Carta a S. M. del Gobernador de Filipinas, Doctor Francisco de Sande. Habla del viaje de los franciscanos a China, relaciones de estos con los agustinos de las Islas, con una descripción detallada de las posesiones que los portugueses tienen en la tierra firme de China. https:// www.upf.edu/asia/projectes/che/s16/sande1580.htm.

Solano, F. de, 1975. El intérprete, uno de los ejes de la aculturación. In Simposio Hispanoamericano de indigenismo histórico, Terceras Jornadas americanistas de la Universidad de Valladolid. Valladolid: Universidad de Valladolid: 265-278.

--, 1988. Cuestionarios para la formación de las Relaciones Geográficas de las Indias, siglos XVI-XIX. Madrid: Consejo Superior de Investigaciones Científicas (CSIC).

--, 1992. Documentos sobre política lingüística en Hispanoamérica (14921800). Madrid: Consejo Superior de Investigaciones Científicas (CSIC).

Tordesillas, A. de,1578. Relación de el viaje que hezimos en china nuestro hermano fray Pedro de Alpharo con otros tres frailes de la orden de Nuestro seraphico padre san francisco de la prouincia de san Joseph del año del señor de mil y quinientos y setenta y nueve años, fecha por mi fray agustín de Tordessillas fraile profeso de la dicha prouincia, Testigo de vista de todo lo que aquí va ascripto. https://www.upf.edu/asia/ projectes/che/s16/tordes.htm.

Vera, S. de, 1589. Carta a S. M. del Gobernador General de Filipinas, Santiago de Vera. Refiere la rebelión que intentaron algunos principales de Filipinas, la contratación con los chinos, falta que hay de gente para la defensa de las Islas; pide ayuda para remediar la necesidad que hay de médico y boticario, etc. Manila. https://www.upf.edu/asia/projectes/ che/s16/vera1589.htm. 
